\title{
Em Relação a Utilização das Metodologias da Pesquisa Qualitativa na Geografia ${ }^{1}$
}

\author{
En Relación a la Utilización de las Metodologías de Investigación \\ Cualitativa en Geografía
}

\author{
Regarding the Use of Qualitative Research Methodologies in \\ Geography
}

\author{
Editha Lisbet Julca Gonza
}

\begin{abstract}
Resumo
Este trabalho tem por objetivo expor algumas reflexões teóricas acerca dos procedimentos metodológicos que sustentam a geografia humana. Para dar conta deste objetivo as interpretações de referenciais teóricos de antropólogos, sociólogos, feministas e humanistas são trazidas ao longo do texto e cuja abordagem interpretativa considera os debates no decorrer da disciplina voltada à metodologia qualitativa na pós-graduação em geografia. Neste sentido, a compreensão da posicionalidade e engajamento no processo de pesquisa são o ponto de partida na reflexividade de interpretação na construção do objeto de pesquisa e na definição dos instrumentos metodológicos e, portanto, sua utilização nos caminhos seguidos pela geografia que olha a dimensão espacial como aspecto crucial de pesquisa.
\end{abstract}

Palavras-Chave: espaço; estratégias de pesquisa; geografia humana; metodologia qualitativa.

\section{Resumen}

Este trabajo expone algunas reflexiones teóricas acerca de los procedimientos metodológicos que sostiene la geografía humana. Para alcanzar este objetivo las interpretaciones de referenciales teóricos de antropólogos, sociólogos, feministas y humanistas son traídas a lo largo del texto y cuyo abordaje interpretativo considera los debates en el curso de la disciplina referida a la metodología cualitativa en el posgrado en geografía. En este sentido, la comprensión de la posicionalidad y compromiso en el proceso de investigación son el punto de partida en la reflexividad de interpretación en la construcción del objeto de investigación y en la definición de los instrumentos metodológicos y, por lo tanto, su utilización en los caminos seguidos por la geografía que mira la dimensión espacial como aspecto crucial de la investigación.

Palabras clave: espacio; estrategias de investigación; geografía humana; metodología cualitativa.

\begin{abstract}
This paper aims to present some theoretical reflections about the methodological procedures that support human geography. In order to realize this goal, interpretations of theoretical references of anthropologists, sociologists, feminists and humanists are brought throughout the text, and whose interpretative approach considers the debates in the course of the discipline focused on the qualitative methodology in postgraduate studies in geography. In this sense, the understanding of positionality and engagement in the research process is the point of departure in the

\footnotetext{
${ }^{1}$ Este texto foi resultado da elaboração do trabalho final da disciplina de "Metodologias de pesquisa qualitativa para geografia", ministrada pelo prof. Dr. Nécio Turra Neto.

${ }^{2}$ Possui graduação em Ciência política e Sociologia pela Universidade Federal de Integração Latino-americana (UNILA); mestrado em Desenvolvimento Territorial e Políticas Públicas pela Universidade Federal Rural do Rio de Janeiro (UFRRJ); doutoranda em geografia pela Universidade Paulista (UNESP), campus Presidente Prudente; eljg90@gmail.com
} 
reflexibility of interpretation in the construction of the research object and in the definition of methodological instruments, and therefore, its use in the paths followed by geography that looks at the spatial dimension as a crucial aspect of research.

Keywords: human geography; qualitative methodology; research strategies; space.

\section{Introdução}

O teor representativo do processo de construção do objeto de pesquisa, relação entre sujeito-objeto e a definição dos instrumentos para responder às indagações propostas no fazer ciência põem em jogo a variedade de facetas do "saber pensar" e do reconhecimento de que somos seres racionais e sobretudo seres emotivos. Isto mostra a complexidade entre a razão e a emoção, entre ser reticentes e ser envolventes profundos, mas que precisamos de ambas para proceder na captação da realidade dialeticamente fora de nós sujeitos subjetivos. São estes elementos que definem o que consideramos importante ou não importante e, de como tratamos a ideia que fazemos da realidade, assim como o que compreendemos das relações espaciais?

Para tentar responder a questão acima farei um percorrido de interpretações e reflexões teóricas da construção do "objeto" de pesquisa e a escolha dos caminhos metodológicos, como processo criativo do pesquisador(a). As interpretações trazidas neste texto são baseadas, principalmente, nas referências teóricas e de debates na sala de aula no decorrer da disciplina de "Metodologias de pesquisa qualitativa para geografia", no Programa de Pós-graduação em Geografia da UNESP/FCT Presidente Prudente. Apoiada nesse contexto, compreendo a pesquisa qualitativa como um processo de tratamento teórico e prático que envolve de maneira mais aprofundada a ação dos sujeitos na vida social, geralmente voltada a estudos de caso e a sua principal fonte de informação é a experiência de diálogo que o pesquisador (a) realiza junto com os sujeitos pesquisados(as) (DEMO, 1987, 2011; TURRA NETO, 2012; GIDDENS, 2012).

Em relação a questão anterior e o contexto da disciplina sobre as metodologias de pesquisa qualitativa, na área da geografia, decorre da necessidade de gerar pontualmente algumas ponderações do exercício metodológico nesta área em específico ${ }^{3}$. Visto que, as questões de metodologia qualitativa (sem desconsiderar a quantitativa), ante todo sujeita-se no entrelaçamento entre teoria e os desafios dialógicos do pesquisador (a) com os sujeitos do

\footnotetext{
${ }^{3}$ Este direcionamento à reflexões da pesquisa qualitativa é um interesse que surge a consequência da minha trajetória acadêmica durante a graduação e atualmente no desenvolvimento da minha pesquisa de doutoranda intitulada: "Disputa por território e formas de organização territorial camponesa no Brasil e no Peru", com a intencionalidade de articular a compreensão espacial e escalar em contextos sócio-políticos.
} 
campo, e o foco nas práticas espaciais é uma especificidade da geografia. Neste caso, as metodologias de pesquisa qualitativa visam propiciar estudos aprofundados principalmente em escalas relativamente pequenas vinculadas à macroprocessos que em primeiro momento não difere das outras áreas das ciências humanas.

O primeiro momento desse texto refere-se ao processo de configuração e delimitação do que se quer estudar. A perspectiva de Geertz (1978) e Haraway (1995) abordam, por exemplo, desde a concepção de cultura como atrelada à trajetória de quem pesquisa e as implicâncias de como traçamos o campo de estudo e o que deixamos de lado de acordo com a realidade que nos interessa, ou seja, como refere Marre (1991) e Giddens (2012), que "ninguém parte do nada”. A posição do pesquisador(a) no campo também são elaboradas desde Zusmán (2011), e como prática do pesquisador(a) na busca em aprender tudo o que pode para levar o necessário para a produção de conhecimento, sob a perspectiva de Latour (2000) e Geertz (1989), os autores referenciam um processo do "olhar treinado", ou seja, refere-se a compreensão de uma cultura a partir de outra.

No segundo momento, considero essa operacionalização e possibilidade(s) de interpretação do sujeito pesquisador(a) e as realidades (nas) que se quer entender, apresentando alguns instrumentos utilizados como estratégia para obter dados e produzir informações. Como por exemplo, a observação participante, história oral, história de vida, entrevistas em profundidade, grupos de discussão, análise de discurso, cartografia social, pesquisa-ação e nenotgrafia representam ${ }^{4}$. Evidencia-se que devemos pensar dialeticamente como constituímos nosso objeto de pesquisa, como interagimos no campo delimitado e nossas opções metodológicas para a interpretação parcial da realidade. Por fim, como conclusão, apresento algumas reflexões acerca do uso das estratégias metodológicas criativas desde a geografia.

\section{Inquietações e recorte espacial}

O enunciado de que "ninguém parte do nada" de Marre (1991) e de Giddens (2012) que "todo problema de pesquisa são enigmas ou lacunas de nossa compreensão", referem-se a uma inevitável ligação à trajetória vivida de quem pesquisa e a impossibilidade de neutralidade dos cientistas. Para os autores, a sociedade está configurada por valores e normas culturais estabelecidas e modificadas constantemente pelos próprios sujeitos. Assim, cada um de nós que

\footnotetext{
${ }^{4}$ As metodologias em destaque neste trabalho foram debatidas em sala de aula em formato de seminários grupais e baseados em referenciais teóricos específicos e em perspectivas práticas na diversidade de projetos de pesquisa entre nós discentes em geografia.
} 
pesquisamos estamos inseridos num contexto histórico que proporciona instrumentos e técnicas que derivam de épocas anteriores para constituir objetos de pesquisa, e sobretudo, do contato com a realidade empírica e o referencial teórico que estamos utilizando, inclusive, que pode estar em constante reformulação.

De acordo com os autores supracitados, o processo de pesquisa envolve estudar as relações humanas, muito diferente da observação de fatos no mundo físico, consiste no reconhecimento de que os seres humanos são autoconscientes e, conferem significados e propósito ao seu próprio fazer-se. Por sua vez, a busca do entendimento mais aprofundado da nossa vida social desde a reunião de dados detalhados, análise e publicação das interpretações é uma ação individual. Trata-se de um movimento intelectual desde o pesquisador(a) e seu contato com a realidade que reformula a teoria, e cuja dinâmica de escolha teórica e empírica dependem dos valores internos do pesquisador(a).

Nas proposições de Marre (1991), a escolha do tema e formulação da pergunta é um entrelaçamento ascendente e descendente entre a empiria e a teoria na construção do objeto. Para o autor, a relevância de abordar um determinado tema, buscar explicações a partir de referencial teórico e empírico, demonstrando que o que está em jogo é o esclarecimento do que acontece nos lugares como especificidades complexas desde a visão de mundo do pesquisador até na escolha do referencial teórico. Todavia, "saber pensar" como processo de operacionalização científica é baseada na teoria, porque ela é mediadora, seja em um percurso ascendente ou descendente do repertório prático-teórico (GEERTZ, 1978; MARRÉ, 1991; DEMO, 2011).

Nesse sentido, o estabelecimento empírico das relações sociais e a aproximação teórica definem a nossa pergunta constituída de implicâncias culturais do pesquisador(a) e dos pesquisados(as). Entretanto, um pouco mais do que explicações e reflexões em nossas práticas, é admitir o olhar parcial e não neutro da realidade complexa (HARAWAY, 1995). Para a autora, a posicionalidade do pesquisador(a) provoca pontos de vista da realidade e olhares sobre o "outro", portanto, espelha as manifestações de poder em contextos políticos no tempo e espaço que se definem como lugar de fala em um contexto em movimento.

Em congruência com a perspectiva de Haraway (1995), já em Geertz (1978) e Pimenta (2009), a pesquisa transcende a própria comunicação da cultura interpretada dos sujeitos estudados, ela seria uma constante interação de intencionalidades que revela a posição do pesquisador(a) de si mesmo(a). Isto é, a nossa formação e a nossa cultura constituem intrinsecamente nosso modo de reconhecer as relevâncias do cenário e tirar conclusões, em 
destacar ou omitir problemas da realidade observável, em nos indignar ou não com determinados problemas, afinal, são pautas de nossos questionamentos, das nossas reflexões, de nossas buscas e tentativas de acerto.

Em outras palavras, devemos reconhecer que a descrição será sempre de quem descreve e não de quem é descrito, logo, é importante o destaque do papel do pesquisador(a), sua trajetória de vida na utilização de estratégias de interação com os sujeitos partícipes da pesquisa (GEERTZ, 1989; HARAWAY, 1995). Até porque a posição do pesquisador(a) no campo, tem relevância na formulação da pesquisa, podendo orientar e definir as atividades e perguntas enquanto processo relacional entre o pesquisador(a) e os sujeitos pesquisados(as). Afinal, a nomeação e construção de campo de estudo expõe a auto reflexibilidade e posição de “autoridade" de quem delimitou e quem vai descrever (CLIFFORD, 1986; ZUSMÁN, 2011; FEGURSON, 2013)

Repensar o trabalho de campo na perspectiva teórica problematiza a delimitação e recorte espacial, sobretudo, a prática espacial na pesquisa. Primeiro porque a ideia de construção de campo, de como delimita-lo pela sua especificidade de campo explorado a volta como espaço "iluminado" de onde alguns aspectos do fenômeno serão desvendados, e que inicialmente não foram pensados pelo pesquisador(a), pode refinar o pensamento da representatividade das relações sociais (CLIFFORD, 1986; SILVA, SILVA, JUNCKES, 2009). Segundo, porque permite refletir a posição do pesquisador(a) e relações de poder no campo, às que tem se atribuído diversas significações e redefinições da contribuição do sentido prático do trabalho de campo e na produção do conhecimento (ZUSMÁN, 2011).

Por conseguinte, a forma de conceber a relação entre pesquisador(a) e as sociedades e espaços como objetos de interesse, manifestam experiências diversas e como processos específicos vinculados a criatividade do pesquisador(a), isto é, como caminho aberto em constante construção em analogia às espacialidades que estão em contínua transformação (ZUSMÁN, 2011). A realidade em questão é sempre aquela que podemos observar desde nosso ponto de vista, portanto, todos os esforços para entendê-la desde o método científico segue sendo "uma pequena fração do cosmos, mesmo aquelas não marcadas pela materialidade". É a intencionalidade de quem "sabe pensar, [que] não faz por fazer, mas sabe por que e como faz", e que está confinado a um espaço, um tempo e horizonte restrito e inacabado (DEMO, 2011, p.8).

O diagrama a seguir, aborda o cenário de prática de pesquisa composta pelas “coincidências" ou melhor pela relação dialógica entre o sujeito e objeto. Assim, a valorização 
do trabalho de campo no processo de problematização reconhece a trajetória de vida do sujeito pesquisador (a) com intencionalidade teórica e prática no entendimento da realidade parcial e reformulação conceitual, e como uma forma lógica contextual e temporal. Além disso, o trabalho de campo reflete a valorização do espaço como relação simultânea entre o pesquisador (a) e o sujeito/objeto, o que pode propiciar possibilidade de alterações qualitativa na formulação dos dados a partir dessa relação. Para isso, nós pesquisadores (as) devemos estar abertos para encontrar o imprevisível e repensar as práticas de pesquisa.

Diagrama 1: A prática espacial de pesquisa.

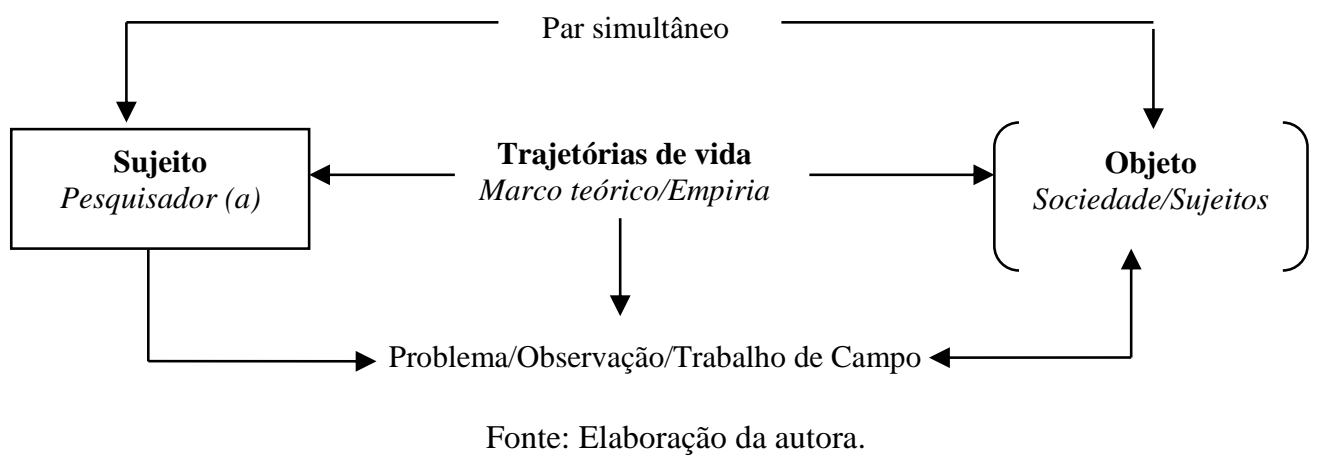

O diagrama 1 expõe o campo como uma espécie de desenho apoiado na observação, considerada como técnica primeira para a delimitação do estudo, e que gera a parcialidade. É o objeto, uma construção do pesquisador (a) para compreender uma dimensão da realidade que está circunscrita a um campo delimitado que deixa "coisas" fora do recorte e tem implicações políticas e epistemológicas. A isto, se adere a análise comparativa do pesquisador (a) no campo e pós campo. Pois, sendo que a prática par simultânea era sobre os "outros", o pesquisador (a) busca apreender tudo que pode levar conhecimento ("coletado" e "necessário") para produzir a escrita que vai elucidar a posição sobre o objeto e transformação do saber para a realidade parcial em questão (LATOUR, 2000; CLIFFORD, 1986).

Até aqui, a reflexão tem a ver com o poder [autoridade] de quem delimita o problema, o campo de estudo, quem escreve, e de representação sobre o que se diz e o que não se diz, o que é singularizado ou generalizado, nas formas de representação e de escuta dos "outros", denota uma posicionalidade individual de quem escreve, quem lê e para quem se produz, pois, o conhecimento é sim para outro (ABU-LUGHOD, 1991). Desse modo, reconhecemos a ordem escalar que cria "os outros" - e que na antropologia tem sido evidenciada nas categorias coloniais e encontros desiguais entre oriente e ocidente, durante a constituição do trabalho de 
campo na perspectiva etnográfica. Sendo assim, a influência da cultura explora o sentido de poder exercido para uma ampliação de contextos que referem intencionalidade de ordem econômica, política e social, por exemplo, quando falamos de migração, é comum nos referir ao recorte histórico desde quem chega e não de quem sai.

Convenientemente nas proposições de Massey (2000; 2008) a respeito do espaço, como pautado pelas nossas experiências entrelaçadas com outras experiências individuais, e, o sentido global do lugar, como a extensão das relações sociais em tempos modernos, podem interceder na compreensão não estreita das nossas experiências no mundo. Pois, intercede na ideia de posicionalidade de quem pesquisa e as variadas percepções acerca da realidade, a (in) visibilidade dos sujeitos, suas histórias e a suas experiências no espaço. Ao mesmo tempo não circunscreve aos sujeitos ao espaço físico, porque são móveis e plurais que participam em múltiplas dimensões e escalas, entrecruzamento de múltiplas interações no contexto de modernidade, procurando definir a especificidade dos lugares que denominamos recorte espacial para o trabalho de campo.

Essas proposições colocam em questão a própria compreensão das interseções escalares do "lugar no mundo" constituído na dinâmica dos próprios sujeitos, e ressalta também, a importância do papel do pesquisador (a) e das distintas estratégias de interação com os sujeitos partícipes da pesquisa que deixam de ser apenas meros informantes para se envolverem no processo de pesquisa (GEERTZ, 1978; GIDDENS, 2012). Pois, a busca de saber sobre "algo" que interessa tem a ver com a visão de mundo de quem pesquisa e com as relações sociais que constituem o espaço e o tempo dedicado a reformulação do problema, no trabalho de campo e na interpretação das informações expostas em narrativas pelo pesquisador(a), que examina clinicamente significados das identidades em locais conectados a outros, porque que não há claramente um lugar delimitado, mas uma associação de lugares, uma potencialidade multilocal ou de relação micro-macro (WINKIN, 1998; MARCUS, 2001).

As razões da prática da pesquisa têm a observação como exigência que permita transcrever e estabelecer fronteiras e contornos que mereçam ser colocados no espaço e no tempo para interpretar uma realidade. É, portanto, o reconhecimento de que o pesquisador (a) é o portador de subjetividades que entra em diálogo com outras subjetividades enquanto trata uma problemática no campo da ciência, tem a ver com o trabalho de campo e seu envolvimento interacional na relação entre teoria e prática. Tem a ver com a escolha do objeto de estudo, com os caminhos propostos de maneira criativa no uso de estratégias que possam explicar significativamente o objeto de pesquisa e construir teorias, ou seja, tem a ver com a competência 
da arte de saber "ver", "ser" (estar com os outros e com nós mesmos) e saber "escrever" (WINKIN, 1998; GUTIERREZ, 2009; TURRA NETO, 2012).

\section{Algumas estratégias para o tratamento da realidade parcial}

A razão de que as metodologias qualitativas na geografia tem como foco de estudo sobre o(s) sujeito(s) e as suas práticas espaciais é um processo flexível que não avança em linha reta 5 . A pesquisa qualitativa faz uso de diversas estratégias que constituem momentos do pensamento em construção, isto é, para conseguir o objetivo proposto na formulação e recorte espacial do objeto "é preciso da rede para pegar peixe" e não só delas, pois "lançando as redes, pode ser que voltem vazias, e não percebermos os pássaros que se assentaram em nossos ombros" (DEMO, 2011, p. 19; 1, p. 108). De modo que a experiência qualitativa não pode ser medida ou regulada para repetição, pois a mesma é irrepetível e o método sem a observação pode obscurecer o caminho das boas ideias.

O pesquisador(a) escolhe e estabelece os contornos do que merece ser pesquisado, seleciona as estratégias de pesquisa (entrevista, observação, história oral, uso de documentos, técnicas de análise das informações, etc.). Essa fase preparatória culmina com a elaboração do projeto, seguida do trabalho de campo, a análise das informações e a redação do relatório de pesquisa. O pesquisador(a) inicia o trabalho de campo com pressuposições sobre o seu problema de pesquisa, originadas do paradigma teórico que orienta o estudo e a produção de informações obtidas pelas observações, anotações no caderno de campo, entrevistas gravadas ou/e anotadas, e logo reconstituídas para redação (SILVA, SILVA, JUNCKES, 2009; TURRA NETO, 2012).

Winkin (1998) destaca a relevância de instrumentos essenciais dos lugares delimitados como campo. Para o autor, o desenho de mapas e o diário de campo são instrumentos essenciais no trabalho de campo que expressam caráter de sistematização e emoção, porque tem a função reflexiva e analítica que permitem construir estratos que conseguimos ver pelos olhos, sentir, desenhar e anotar (incluindo as angustias) feitas no instante de ter estado cara a cara com o

\footnotetext{
${ }^{5} \mathrm{O}$ processo de pesquisa qualitativa ao igual que a quantitativa muitas vezes é vista como sequencial: (1) A pergunta sobre um fenômeno como base para definição do problema a partir de um analises teórico que analisa o "terreno"; (2) a formulação de hipóteses ou afirmações que fazemos sobre o assunto (que pode ser corroborada o não); (3) a definição de variáveis que possam ser verificáveis (Variável dependente e variável independente); (4) elaboração de instrumentos (questionários, entrevistas, etc.), coleta de dados em trabalho de campo e a aplicação dos instrumentos; (5) analises de dados para a verificação da hipótese; (6) conclusões que pode conter sugestões e as limitações no processo da pesquisa; e por fim, (7) a elaboração do relatório que descreve o processo de todos esses passos. Porém, a pesquisa qualitativa substancialmente pode ser circular e não como passos lineares (SPRADLEY, 1980, p. 29).
} 
"outro". Neste sentido, a escolha de estratégias metodológicas (algumas delas sistematizadas na Tabela 1), é sabendo a natureza das informações que se precisa para explicar o objeto de pesquisa já definido, seria uma criação única e não uma técnica repetitiva. Sendo que, "a presença do pesquisador (a) sempre está modificando a dinâmica das relações do grupo, e esta variável dever ser considerada permanentemente”. (SILVA, SILVA, JUNCKES, 2009, p. 62).

Tabela 1. Metodologias para a pesquisa qualitativa

\begin{tabular}{|c|c|c|}
\hline Metodologias & Definições Conceituais & Vantagens/Limitações \\
\hline $\begin{array}{l}\text { Observação } \\
\text { participante }\end{array}$ & $\begin{array}{l}\text { Processo apropriado para capturar as } \\
\text { dinâmicas e interações da vida cotidiana, e } \\
\text { em que se estabelecem relações multilaterais } \\
\text { e de longo prazo entre o pesquisador(a) e } \\
\text { grupos sociais (FOOTE-WHYTE, 1980). }\end{array}$ & $\begin{array}{l}\text { - } \begin{array}{l}\text { Explicações dos sujeitos acerca } \\
\text { pesquisador(a). }\end{array} \\
\text { - Integração e inserção no cotidiano. } \\
\text { - Permite considerar ao ambiente físico e as } \\
\text { interações que nele ocorrem. } \\
\text { - Requer comparação constante dos dados. }\end{array}$ \\
\hline $\begin{array}{c}\text { História Oral e } \\
\text { Entrevistas }\end{array}$ & $\begin{array}{l}\text { Para obter informações da memória do sujeito } \\
\text { que não estão documentadas, é um passado } \\
\text { relembrado desde várias perspectivas, e, } \\
\text { acessar à parte mental das pessoas mediante } \\
\text { entrevistas (AMADO, 1995). }\end{array}$ & $\begin{array}{l}\text { - Transmite e reelabora vivências individuais e } \\
\text { coletivas dos informantes com práticas sociais de } \\
\text { outras épocas e grupos. } \\
\text { - Se confunde "o vivido e o recordado, entre } \\
\text { experiência e memória, entre o que se passou e o } \\
\text { que se recorda daquilo que se passou". } \\
\text { - Embora as memorias sejam sociais, um conjunto } \\
\text { de memorias pertencem a uma única pessoa. }\end{array}$ \\
\hline $\begin{array}{l}\text { Grupos de } \\
\text { Discussão }\end{array}$ & $\begin{array}{l}\text { Técnica que reúne um grupo de pessoas em } \\
\text { um determinado local e período para produzir } \\
\text { informações mediante dialogo e debate sobre } \\
\text { um tema específico (CRUZ NETO, } \\
\text { MOREIRA, SUCENA, 2002). }\end{array}$ & $\begin{array}{l}\text { - Reflexão expressa mediante a fala dos } \\
\text { participantes. } \\
\text { - } \begin{array}{l}\text { Sobrecarga tarefas a um pesquisador(a) } \\
\text { (mediador, observador, digitador, entre outros), } \\
\text { durante a sua aplicação. }\end{array}\end{array}$ \\
\hline $\begin{array}{l}\text { Análise do } \\
\text { Discurso }\end{array}$ & $\begin{array}{l}\text { Procedimento relacionado à interpretação ou } \\
\text { releitura de fala (s) obtidas mediante } \\
\text { entrevistas que poderá revelar os sentidos } \\
\text { produzidos verbalmente (língua) e não } \\
\text { verbais (imagens, fotografias ou linguagens } \\
\text { corpóreas) (CAREGNATO, MUTTI, 2006; } \\
\text { SILVA, SILVA, 2016). }\end{array}$ & $\begin{array}{l}\text { - Codificação de variáveis centrais dos discursos } \\
\text { relacionado a um contexto socio-histórico. } \\
\text { - Não abre mão da língua como materialidade } \\
\text { - Interpretação sempre passível de equívoco. }\end{array}$ \\
\hline $\begin{array}{l}\text { Pesquisa } \\
\text { Ação }\end{array}$ & $\begin{array}{l}\text { Uma forma de investigação-ação que busca } \\
\text { informar a ação de pesquisa da própria prática } \\
\text { para melhora-la atendendo a critérios comuns } \\
\text { a outros tipos de pesquisa acadêmica (TRIPP, } \\
\text { 2005). }\end{array}$ & $\begin{array}{l}\text { - Recurso para aprendizado da própria experiência. } \\
\text { - Aprofundamento da projeção e implementação } \\
\text { do trabalho de campo }\end{array}$ \\
\hline $\begin{array}{l}\text { Cartografia } \\
\text { Social }\end{array}$ & $\begin{array}{l}\text { "Um método para ser experimentado e } \\
\text { assumido como atitude" (MEJIA, 2015, p. } \\
\text { 107). É um processo colaborativo para } \\
\text { mapear as "relações das diferenças", } \\
\text { interações e tensões, subjetividades, práticas } \\
\text { de resistência e de liberdade (PRADO } \\
\text { FILHO, TETTI, 2013, p. 47; OSLENDER, } \\
\text { 2015). }\end{array}$ & $\begin{array}{l}\text { - O mapeamento das subjetividades pode mostrar } \\
\text { as posicionalidades em interação. } \\
\text { - Acompanha processos e não a representação de } \\
\text { sujeitos, isto é mapeamento das relações. }\end{array}$ \\
\hline Netnografia & $\begin{array}{l}\text { Pode ajudar a conhecer um pouco mais sobre } \\
\text { as relações sociais mediadas pela tecnologia } \\
\text { e estabelecendo contato com internautas de } \\
\text { todos do mundo (GUTIERREZ, 2009, p. } 10 \text {; } \\
\text { COUTO JR, 2013, p. 87). }\end{array}$ & $\begin{array}{l}\text { - Aproximar sujeitos geograficamente distantes. } \\
\text { - Capturar as marcas do cotidiano on-line de } \\
\text { internautas } \\
\text { Mapear a teia de relações que se criam e recriam } \\
\text { no fluxo de informações e nas interações que } \\
\text { movimentam as redes } \\
\text { - Não exige a presença física do pesquisador (a). }\end{array}$ \\
\hline
\end{tabular}


A aplicação das metodologias sistematizadas no diagrama 2 representa uma grande potencialidade no desenvolvimento do trabalho de campo, o que significa que a sua utilidade são oportunidade para podermos nos envolver no campo e produzir informações com os sujeitos pesquisados (as), buscando construir compreensões mais aprofundadas da ação individual no contexto da vida social (GIDDENS, 2012). As metodologias a disposição dos pesquisadores (as) em determinada época dão também contribuições individuais para o (a) pesquisador (a) e dos modos como são utilizadas na produção de informações. A escolha destas metodologias, obviamente, é acondicionada a objetivos da pesquisa qualitativa e não regida por fórmulas matemáticas ou de amostragem.

As definições conceituais dessas metodologias acentuam a sua relevância enquanto ao tipo de informação que se quer produzir de acordo a referenciais bibliográficos principais para cada uma delas. Chama a atenção o fato de que todas elas não acomodam aos sujeitos de pesquisa em sua condição do "outro", mas ao desvendamento de aspectos que o pesquisador (a) considere ou não relevantes sobre o protagonismo dos sujeitos pesquisados (as) e suas práticas espaciais. O que prevalece é um olhar mensurador sobre questões cotidianas e de interação constante entre sujeitos pesquisadores e sujeitos (também práticas) dos pesquisados (as), sem deixar o cunho cultural na margem, mas como fator causal de envolvimento no campo ou de limitações de "captura" com saber técnico.

Foote-Whyte (1980) e Amado (1995), referenciais de grande relevância na observação participante e história oral. No diagrama 2, respetivamente, expusermos aqueles processos que contrapõem relações multilaterais presentes e memorias do que se passou. Embora antagônicas na sua compreensão temporal, proporcionam meios para apreender dos componentes da experiência na noção do processo da vida social, "sem desconsiderar que o conjunto de memórias é pertencente a uma única pessoa”. Além disso, a observação participante pode se misturar ou ser conduzida em conjunto com outras metodologias, mas o que a diferencia dos outros é que pode conferir e distinguir fenômenos no lugar do campo.

No caso do Historia Oral, Grupo de discussão, Análise de discurso e a Cartografia social desde os autores citados nos quadros de conceituação de cada um deles referem a um processo de investigação que se constrói literalmente desde a fala dos sujeitos pesquisados (as) e de elementos simbólicos. Em decorrência da aplicabilidade de entrevistas em todas essas metodologias os sentidos verbais e não verbais, individuais ou grupais, podem proporcionar diferentes sentidos relacionados ao contexto sócio histórico. Neste aspecto, também podemos considerar a netnografia, desde o elemento da escrita, um outro caminho estratégico em que a 
pesquisa tem adotado como "ambiente virtual", porque "relaciona-se com ir em algum lugar, no sentido literal da expressão, para observar e interagir", e constrói gradualmente "outros caminhos teórico-metodológicas adotados pelo pesquisador(a) em parceria com os sujeitos" (GUTIERREZ, 2009; COUTO JR, 2013, p. 88).

A Pesquisa Ação e a Observação Participante são metodologias para rever os nossos procedimentos durante a pesquisa no campo, atendendo às perspectivas dos sujeitos sobre nós pesquisadores (as), e a repensar nossas práticas no campo, e melhora-la, fazendo mudanças para quando os rumos da pesquisa prática exijam faze-la (TRIPP, 2005; FOOTE-WHYTE, 1980). Pois, os estágios da pesquisa não são sequencialmente depois de outros, há uma certa quantidade de "jeitinhos", que "é como as receitas apresentadas em um livro de culinária e o processo real de preparar a comida. Pessoas que são experientes na cozinha muitas vezes nem seguem receitas, mas a sua comida pode ficar melhor do que a preparada por aqueles que seguem" (GIDDENS, 2012, p. 47).

Contudo, desde a perspectiva de Geertz (1989) e Zusmán (2011), que realçam a experiência do trabalho de campo, desde a antropologia e a geografia, como "a própria disposição de um certo grau de solidão e desconforto físico" do pesquisador (a), e, como o acompanhamento da evolução e transformação das realidades sociais "sem receita de bolo". Em que as estratégias metodológicas acima sintetizadas, compõem procedimentos de relações dialógicas e de tensionamentos entre pesquisador (a) e o objeto de pesquisa, e, também da veracidade de "ter estado lá". Ante todo, as formas das descrições feitas "aqui" acerca das interpretações do campo, "mais do que lá", por isso revela ainda mais a descrição de "aqui".

\section{Conclusões}

Ao longo do texto tenho exposto interpretações teóricas do percurso de constituição do objeto de pesquisa e estratégias metodológicas relevantes no trabalho de campo, e que envolvem, sobretudo, questões racionais e emotivas que se estende mais além de mapeamentos dos lugares, mas de permissões e formas de experienciá-los, e também de explica-los. Essa eleição teórica das metodologias qualitativas que alimentou este texto pode ser descrita como de multisituada, em seu sentido de repensar o lugar de fala e das experiências íntimas e públicas, individuais e coletivas, de enunciações ou de omissões na construção de escrita, vinculada ao global no seu sentido de contexto sociopolítico. Assim, os desafios metodológicos que a geografia, no seu sentido de multiescalaridade, perpassam os entrelaçamentos das relações sociais entre pesquisador (a) e os sujeitos pesquisados (as). 
A primeira reflexão que destaco é sobre o pressuposto que somos racionais e emotivos, ou seja, o conhecimento como corporificado. Isto é, a interpretação da realidade do ser social enquanto a sua experiência e seu contexto histórico, implica geração de conhecimento de modo relacional próprio ao espaço e tempo do cientista, com isso, o significado da realidade sob as normas em sociedade dado por padrões de conduta, emoções e decisões frente a natureza do ser que se estuda, assume um papel dialético de subjetividades. Onde a minha posição de pesquisadora não está fora dos embates da estrutura social, o "direito" falar ou não do "outro", seja na constituição do objeto (ações das pessoas) e processos de pesquisa, mas é preciso assumir o ônus de autoria como leitura parcial da realidade.

A ideia de recorte da realidade espacial é uma ação protagonizada por quem pesquisa sob a responsabilidade individual que apresenta as ações humanas de outros indivíduos para interpretar suas próprias ações e o modo de ver as coisas, ou mesmo, de como se percebe a vida. Em decorrência disso, a segunda reflexão, se associa a eleição do lugar de estudo como escala material e subjetiva de acordo à nossa história vivenciada, dimensionada e apreendida com a constituição da formulação do problema e o recorte espaço-temporal. Porque é como interpreto o lugar no sentido racional e de afetividade em todo o processo de pesquisa, enquanto tempo visível, sentimentos e de concretude, que posso encontrar metodologias para a compreensão das espacialidades.

Nesse sentido, é importante sinalar que como pesquisadoras(es), desde nossos corpos e subjetividades, não estamos isentos de críticas e interesses, mas temos a assumir a responsabilidade em cada explicação investigada. Porque a teoria e os caminhos metodológicos que é escolhido vai criar (in) visibilidades de determinados grupos e de práticas espaciais. Então, prestar atenção ao processo de pesquisa qualitativa realça a desconstruir a ideia das passividades dos sujeitos (“outros") na pesquisa.

Assim, a disciplina "Metodologias de pesquisa qualitativa para geografia" tem vindo a contribuir ao entendimento das dialogicidades e tensionamentos no processo do fazer ciência geográfica. Especialmente nas pesquisas que tem como foco aos sujeitos e as suas práticas espaciais, que interatuam com nas múltiplas dimensões da localização do pesquisador (a) enquanto à gênero, ração, nacionalidade, sexualidade e outras marcas materiais e subjetivas que se encontram no processo de pesquisa. 


\section{Referências}

AMADO, J. O grande mentiroso: tradição, veracidade e imaginação em história oral. História, São Paulo, 14, p. 125-136, 1995.

CAREGNATO, R.C.A, MUTTI, R. Pesquisa qualitativa: Análise de discurso versus análise de conteúdo. Texto Contexto Enferm, Florianópolis, 2006, 679-684.

CLIFFORD, J. On Ethnographic Allegory. In: James Clifford \& George Marcus (orgs.). Writing Culture. The Poetics and Politics of Ethnography. Berkeley: University of California Press. 1986, p. 98-121.

COUTO JR, D. R. do. Etnografia virtual e as contribuições de Mikhail Bakhtin na pesquisa com internautas. Revista Teias, Rio de Janeiro, v: 14, no 31, p. 97 - 108, maio/agosto 2013.

DEMO, P. Praticar ciência: metodologias do conhecimento científico. São Paulo: Saraiva, 2011.

DEMO, P. Saber pensar. $7^{\text {a }}$ Ed. São Paulo: Cortez, Instituto Paulo Freire, 2011, p. 11-47.

FERGUSON, J. Declarations of dependence: labour, personhood, and welfare in southern Africa. Journal of the Royal Anthropological Institute, 19: 223-242. 2013.

GEERTZ, C. A interpretação das culturas. Rio de Janeiro: Zahar, 1978.

GEERTZ, C. Estar lá, escrever aqui. In: Dialogo, São Paulo n 22, 1989, p. 58-63.

GUTIERREZ, S. de S. A etnografia virtual na pesquisa de abordagem dialética em redes sociais on-line. In: 32 Reunião Anual da ANPEd, 2009, Caxambu. Sociedade, cultura e educação: novas regulações?, 2009.

CRUZ NETO, O.; MOREIRA, M. R.; SUCENA, L. F. M. Grupos focais e pesquisa social qualitativa: o debate orientado como técnica de investigação. In: Anais... Encontro da Associação Brasileira de Estudos Populacionais, XIII, Ouro Preto, 04 a 08 de novembro, de 2002.

HARAWAY, D. Saberes Localizados. A questão da ciência para o feminismo e o privilegio da perspectiva parcial. In: Cadernos Pagu (5), 1995, p. 07-41.

LATOUR, B. Ciência em ação: como seguir cientistas e engenheiros sociedade afora. Tradução de Ivone C. Benedetti. Editora Unesp, 2000.

MARRE, J. A. L. A construção do objeto científico na investigação empírica. Cascavel: Seminário de Pesquisa do Oeste do Paraná - UNIOESTE, 1991. 
OSLENDER, U. Ontologia relacional y cartografia social: ¿hacia um contra-mapeo emancipador, o ilusión contra-hegemónica? Tabula Raza. Bogotá - Colombia, No.26: 247-262, enero-junio 2017.

SILVA, E. A.; SILVA, J. M. Ofício, engenho e arte: inspiração e técnica na análise de dados qualitativos. Revista Latino-americana de Geografia e Gênero, Ponta Grossa, v. 7, n. 1, p. 132 - 154, jan. / jul. 2016.

TRIPP, D. Pesquisa-ação: uma introdução metodológica. Educação e Pesquisa, São Paulo, v. 31, n. 3, p. 443-466, set. /dez. 2005.

TURRA NETO, N. Pesquisa Qualitativa Em Geografia. In: XVII Encontro Nacional de Geógrafos - XVII ENG, 2012, Belo Horizonte. Anais do XVII Encontro Nacional de Geógrafos: entre escalas, poderes, ações, geografias, 2012.

WINKIN, Y. Descer ao campo. In: A nova comunicação: da teoria ao trabalho de campo. Campinas: Papirus, 1998. p. $129-145$.

ZUSMAN, P. La tradición del trabajo de campo e geografía. In: Geograficando. Universidad Nacional de La Plata. Facultad de Humanidades y Ciencias de la Educación. Departamento de Geografía. 2011, p. 15-32. 